\title{
Subtype Distribution of Blastocystis in Communities along the Chao Phraya River, Thailand
}

\author{
Attakorn Palasuwan', Duangdao Palasuwan', Aongart Mahittikorn², Rachatawan Chiabchalard², Valery Combes ${ }^{3}$, \\ Supaluk Popruk ${ }^{2, *}$ \\ ${ }^{1}$ Department of Clinical Microscopy, Faculty of Allied Health Sciences, Chulalongkorn University, Bangkok, Thailand; '2Department of Protozoology, \\ Faculty of Tropical Medicine, Mahidol University, Bangkok 10400, Thailand; 'Faculty of Sciences, School of Life Sciences, University of Technology, \\ Sydney, Australia
}

\begin{abstract}
Blastocystis is a common zoonotic enteric protozoan that has been classified into 17 distinct subtypes (STs). A cross-sectional study was conducted to determine the prevalence and subtype distributions of Blastocystis in villagers living along the Chao Phraya River, Ayutthaya Province, Thailand, and to assess the risk of zoonotic infection. In total, 220 stool samples were collected, and DNA was extracted. PCR and sequencing were performed with primers targeting the small-subunit ribosomal RNA (SSU rRNA) genes. Blastocystis was present in 5.9\% (13/220) of samples, and ST3 (5.0\%; $11 / 220)$ was the predominant subtype, followed by ST2 $(0.45 \% ; 1 / 220)$ and ST6 $(0.45 \% ; 1 / 220)$. Phylogenetic trees were constructed with the maximum-likelihood method based on the Hasegawa-Kishino-Yano + $\mathrm{G}+\mathrm{I}$ model, neighbor-joining, and maximum parsimony methods. The percentage of bootstrapped trees in which the associated taxa clustered together was relatively high. All the sequences of the Blastocystis-positive samples (KU051524-KU051536) were closely related to those from animals (pig, cattle, and chicken), indicating a zoonotic risk. Therefore, the villagers require proper health education, especially regarding the prevention of parasitic infection, to improve their personal hygiene and community health. Further studies are required to investigate the Blastocystis STs in the animals living in these villages.
\end{abstract}

Key words: Blastocystis, subtype, zoonotic risk, Chao Phraya River, Thailand

\section{INTRODUCTION}

Blastocystis is an enteric zoonotic protozoan found in humans and many kinds of animals [1]. It is one of the most commonly detected protozoans in parasitological surveys, with high infection rates in developing countries [2]. Transmission can occur from humans to humans, humans to animals, and animals to humans via the fecal-oral route.

Several methods are used to diagnose Blastocystis infection, including direct examination, culture, and PCR. Among these, PCR is the most powerful, sensitive, and specific detection technique for Blastocystis and can be used for subtyping analyses [3]. At least 17 distinct subtypes (STs) of Blastocystis have been identified in humans, non-human primates, mammals, and avian hosts, based on the analysis of the small-

- Received 14 March 2016, revised 19 May 2016, accepted 8 June 2016.

*Corresponding author (supaluk.pop@mahidol.ac.th)

(c) 2016, Korean Society for Parasitology and Tropical Medicine

This is an Open Access article distributed under the terms of the Creative Commons Attribution Non-Commercial License (http://creativecommons.org/licenses/by-nc/4.0) which permits unrestricted non-commercial use, distribution, and reproduction in any

medium, provided the original work is properly cited. subunit ribosomal RNA (SSU rRNA) genes [4]. ST1-ST9 have been reported in humans, and ST1-ST4 are most common $[5,6]$. Some Blastocystis STs detected in humans have also been identified in animals. This suggests that animals can act as reservoirs for this protozoan and may be linked to its zoonotic transmission. Therefore, subtyping of this protozoan allows us to understand the interactions between humans and animals in specific communities.

The Chao Phraya River is one of the most important water sources in Thailand. Many communities and animal husbandry activities are located along this river. Importantly, it is the source of water for the people living along it, including those in Ayutthaya Province. It is possible that domestic animals, wildlife, and communities shed intestinal parasites into the river, readily spreading them to the environment, and thus distributing parasitic diseases among the communities.

Until now, limited data have been available on the prevalence and subtypes of Blastocystis in the communities living along the Chao Phraya River. Such data could be used to support and promote the health and quality of life of the humans and animals in the area, and to improve the interactions be- 
tween them. In this study, we investigated the prevalence and subtype distributions of Blastocystis among the villagers living along the Chao Phraya River.

\section{MATERIALS AND METHODS}

\section{Collection of human stool samples}

A cross-sectional study was conducted in September-October 2015 in 5 subdistricts (Khanon Luang, Talat Kriap, Ban Pho, Wat Yom, and Ko Koet) in the Bang Pa-In district of Ayutthaya Province, in central Thailand. These subdistricts are situated along the sides of the Chao Phraya River, and the villagers work in agriculture and live in close contact with animals, as shown in Fig. 1. Moreover, there has been some concern about the health of the villagers. In total, 220 human stool samples were collected. The participants ranged in age from 1 to 75 years. No participant complained of any gastrointestinal symptoms, such as abdominal pain or diarrhea. The specific instructions for collecting the stool samples and avoiding their contamination were clearly explained to all the participants. The stool samples were kept cool during transportation to the laboratory, and were then stored at $-20^{\circ} \mathrm{C}$ until DNA extraction. The study protocol was approved by the Ethics Review Committee for Re-

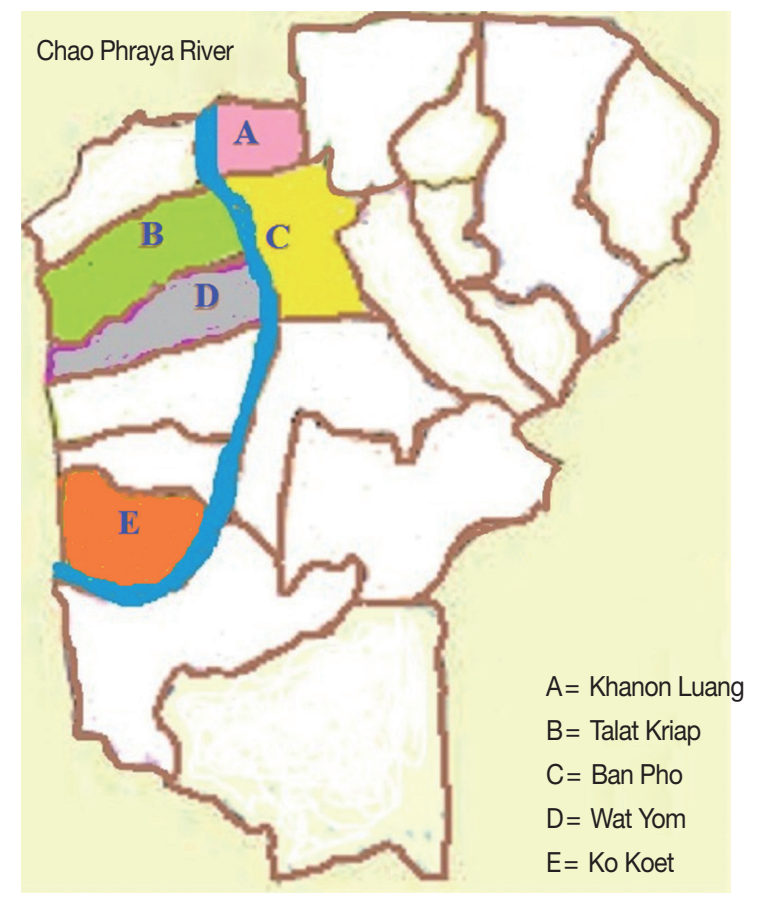

Fig. 1. Map of the study areas. Bang Pa-In district, Ayutthaya Province, central Thailand. search Involving Human Research Subjects, Health Sciences Group, Chulalongkorn University, Bangkok, Thailand (COA no. 152/2558).

\section{DNA extraction from stool samples and PCR amplification}

DNA was extracted directly from all the fresh stool samples using the PSP® Spin Stool DNA Kit (STRATEC Molecular GmbH, Berlin, Germany), according to the manufacturer's instructions. DNA samples were stored at $-20^{\circ} \mathrm{C}$ until analysis.

Blastocystis was detected, and the STs were characterized with a nested PCR analysis of the DNA from the collected stool samples. The primer sets and conditions used have been published previously and are specific for the partial SSU rRNA genes, which differentiate the subtypes of Blastocystis: external primer set, RD3 5'-GGGATCCTGATCCTTCCGCAGGTTCACCT

Table 1. Reference Blastocystis sequences used for the phylogenetic analysis in this study

\begin{tabular}{|c|c|c|c|}
\hline Subtype & Host & Accession no. & Location \\
\hline \multirow[t]{3}{*}{1} & Pig & AB107961 & Japan [21] \\
\hline & Human & U51151 & USA [22] \\
\hline & Vervet monkey & AB107968 & Japan [21] \\
\hline \multirow[t]{3}{*}{2} & Pig & EU445487 & Philippines [23] \\
\hline & Human & AB070987 & Japan [24] \\
\hline & Pig-tailed macaque & AB107969 & Japan [21] \\
\hline \multirow[t]{4}{*}{3} & Human & AB070992 & Japan [24] \\
\hline & Baboon & HQ909890 & Denmark [25] \\
\hline & Cattle & AB107965 & Japan [21] \\
\hline & Pig & AB107963 & Japan [21] \\
\hline \multirow[t]{3}{*}{4} & Rat & AB071000 & Japan [24] \\
\hline & Human & JN682513 & Denmark [26] \\
\hline & Guinea pig & U51152 & USA [22] \\
\hline \multirow[t]{3}{*}{5} & Pig & AB107964 & Japan [21] \\
\hline & Cattle & AB107966 & Japan [21] \\
\hline & Human & EF468654 & China [27] \\
\hline \multirow[t]{2}{*}{6} & Human & AB091237 & Japan [24] \\
\hline & Chicken & EU445485 & Philippines [23] \\
\hline \multirow[t]{2}{*}{7} & Human & AF408427 & Japan [24] \\
\hline & Duck & AY135412 & France [28] \\
\hline \multirow[t]{2}{*}{8} & Lemur & AB107970 & Japan [21] \\
\hline & Pheasant & AB107971 & Japan [21] \\
\hline \multirow[t]{2}{*}{9} & Human & AF408426 & Japan [14] \\
\hline & Human & KC138681 & Denmark [29] \\
\hline 10 & Camel & KC148207 & UK [4] \\
\hline 11 & Elephant & GU256922 & Australia [30] \\
\hline 12 & Giraffe & GU256902 & Australia [30] \\
\hline 13 & Mouse deer & KC148209 & UK [4] \\
\hline 14 & Cattle & KC148205 & UK [4] \\
\hline 15 & Gibbon & KC148211 & UK [4] \\
\hline 16 & Red kangaroo & EU427514 & Japan [31] \\
\hline 17 & Gundi & KC148208 & UK [4] \\
\hline
\end{tabular}


AC-3' and RD5 5'-GGAAGCTTATCTGGTTGATCCTGCCAGTA$3^{\prime}[7]$; and internal primer set, forward 5'-GGAGGTAGTGACAA TAAATC-3' and reverse 5'-ACTAGGAATTCCTCGTTC ATG-3' [2]. PCR products were about 1,100 base pairs (bp) in length and were detected with $1.5 \%$ agarose gel electrophoresis. DNA in the gels was stained with ethidium bromide and visualized under a transilluminator.

\section{DNA sequencing and phylogenetic reconstruction}

All the positive samples were sequenced with an ABI 3730 $\mathrm{XL}$ sequencer, using fluorescent-dye terminator sequencing by Bio Basic Canada Inc. (Ontario, Canada). The positive sample sequences were read and edited with BioEdit (http://www. mbio.ncsu.edu/bioedit/bioedit.html). The Blastocystis STs of the positive samples were identified by comparing them with the 17 Blastocystis STs available in the GenBank database using the Basic Local Alignment Search Tool (BLAST; http://blast. ncbi.nlm.nih.gov/Blast.cgi) as shown in Table 1. A multiple sequence alignment was constructed with Clustal W [8]. Phylogenetic reconstructions were performed with MEGA 6.0 [9]. The phylogenetic trees were constructed with maximum-likelihood (ML) method based on the Hasegawa-Kishino-Yano + G (gamma distribution) + I (invariant) model (best-fit substitution model), and also neighbor-joining (NJ) and maximum parsimony (MP) methods. Bootstrap values were calculated with 1,000 replicates. Proteromonas lacertae (accession no. U37108), which is closely related to Blastocystis, was used as the outgroup.

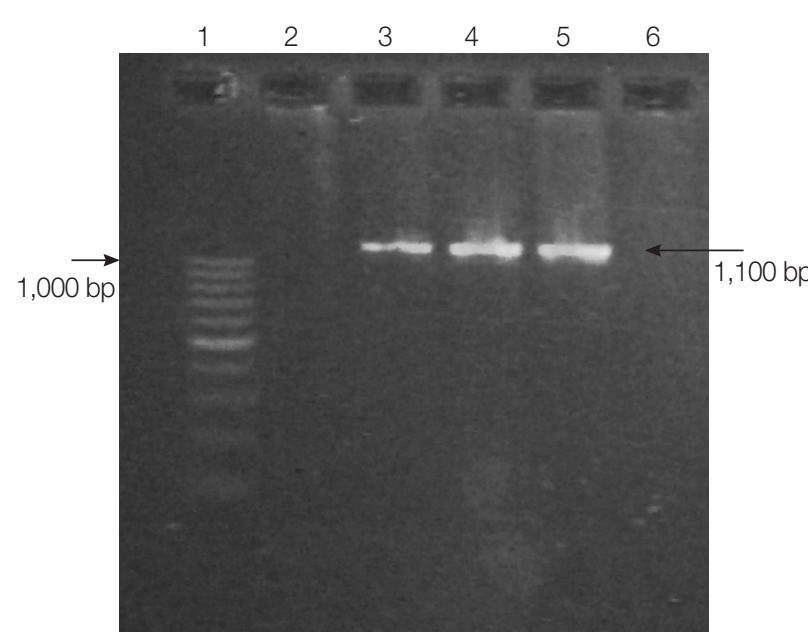

Fig. 2. Gel electrophoresis of PCR amplification products. Lane 1, 100-bp DNA marker; lane 2, negative control; lane 3, positive control (Blastocystis); lanes 4-5, positive samples containing Blastocystis; lane 6, negative sample without Blastocystis.

\section{Statistical analysis}

A descriptive analysis of percentages was used to explore the positive stool samples and ST distributions of Blastocystis.

\section{RESULTS}

\section{Prevalence of Blastocystis determined with nested PCR}

The overall prevalence of Blastocystis infection detected with nested PCR in this study was 5.9\% (13/220). Fig. 2 shows positive PCR results for Blastocystis. PCR products were about $1,100 \mathrm{bp}$ in length.

\section{Subtype characterization of Blastocystis in positive stool samples}

The Blastocystis STs were identified with direct DNA sequencing. BLAST results for positive samples were shown in Table 2. Only ST3, ST2, and ST6 were detected. ST3 $(5.0 \% ; 11 / 220)$ was the predominant subtype, followed by ST2 $(0.45 \% ; 1 / 220)$ and ST6 $(0.45 \% ; 1 / 220)$ as shown in Table 3 . Table 4 shows the ST distributions of Blastocystis according to geographic subdistricts. The ages of the Blastocystis-infected individuals ranged from approximately 30 to 70 years, except for 2 infected children from Talat Kriap and Khanon Luang, whose ages were 1 year (ST6 infected) and 8 years (ST3 infected), respectively.

Table 2. BLAST results for positive samples in this study

\begin{tabular}{lccc}
\hline Sample & \% Identity & \% Coverage & Accession no. \\
\hline KU051524 & 99 & 98 & AB107963 (ST3) \\
KU051525 & 98 & 97 & AB107963 (ST3) \\
KU051526 & 99 & 97 & GU992412 (ST2) \\
KU051527 & 99 & 98 & AB107963 (ST3) \\
KU051528 & 99 & 97 & EU445496 (ST3) \\
KU051529 & 99 & 98 & AB107963 (ST3) \\
KU051530 & 99 & 97 & AB107963 (ST3) \\
KU051531 & 99 & 99 & AB107963 (ST3) \\
KU051532 & 99 & 98 & AB107963 (ST3) \\
KU051533 & 99 & 96 & AB091237 (ST6) \\
KU051534 & 99 & 98 & AB107963 (ST3) \\
KU051535 & 99 & 96 & AB107963 (ST3) \\
KU051536 & 99 & 97 & AB107965 (ST3) \\
\hline
\end{tabular}

Table 3. Subtype distribution of Blastocystis in this study

\begin{tabular}{lc}
\hline Subtype & No. of positive samples (\%) \\
\hline 2 & $1 / 220(0.45)$ \\
3 & $11 / 220(5.0)$ \\
6 & $1 / 220(0.45)$ \\
Total & $13 / 220(5.9)$ \\
\hline
\end{tabular}




\section{Phylogenetic reconstruction and genetic divergence of Blastocystis isolates}

The ML tree of Blastocystis constructed from SSU rRNA gene sequences is shown in Fig 3. The ML method was based on the Hasegawa-Kishino-Yano+G+I model. The percentage of bootstrapped trees in which the associated taxa clustered together was relatively high. The ML tree, upon which the SSU rRNA gene sequences of the Blastocystis-positive samples were compared with 17 reference sequences in the GenBank database, classified KU051524, KU051525, KU051527-KU051530, KU051532, and KU051534-KU051536 as ST3, KU051526 as ST2, and KU051533

Table 4. Subtype distribution of Blastocystis according to subdistrict

\begin{tabular}{lcr}
\hline Subdistrict & Subtype & No. of positive samples (\%) \\
\hline Khanon Luang & 2 & $1 / 58(1.7)$ \\
& 3 & $4 / 58(6.9)$ \\
Talat Kriap & 3 & $2 / 18(11.1)$ \\
& 6 & $1 / 18(5.6)$ \\
Ban Pho & 3 & $3 / 66(4.5)$ \\
Wat Yom & 3 & $2 / 6(3.2)$ \\
Ko Koet & - & $0 / 15(0.0)$ \\
Total & & $13 / 220(5.9)$ \\
\hline
\end{tabular}

as ST6. All the sequences from the Blastocystis-positive samples were closely related to animal sequences (from pigs, cattle, and chickens). The NJ and MP trees showed the same clustering patterns as the ML tree (data not shown).

\section{DISCUSSION}

The relatively low (5.9\%) prevalence of Blastocystis observed in this study might be attributable to the characteristics of the study area, where public utilities, such as tap water, are available to almost every household. Therefore, the villagers are protected from infection because they use treated water in their daily activities. The prevalence of Blastocystis infection is higher in developing countries than in developed countries. However, it varies from country to country, and within the same country $[2,10,11]$. In Thailand, Blastocystis infection has been reported at rates as high as $37.2 \%$ [12]. Several risk factors seem to be associated with Blastocystis infection, including poor personal hygiene and high-risk behavior, poor community sanitation, socioeconomic status, lifestyle, and the culture of the population. Blastocystis can also infect a range of animals, including

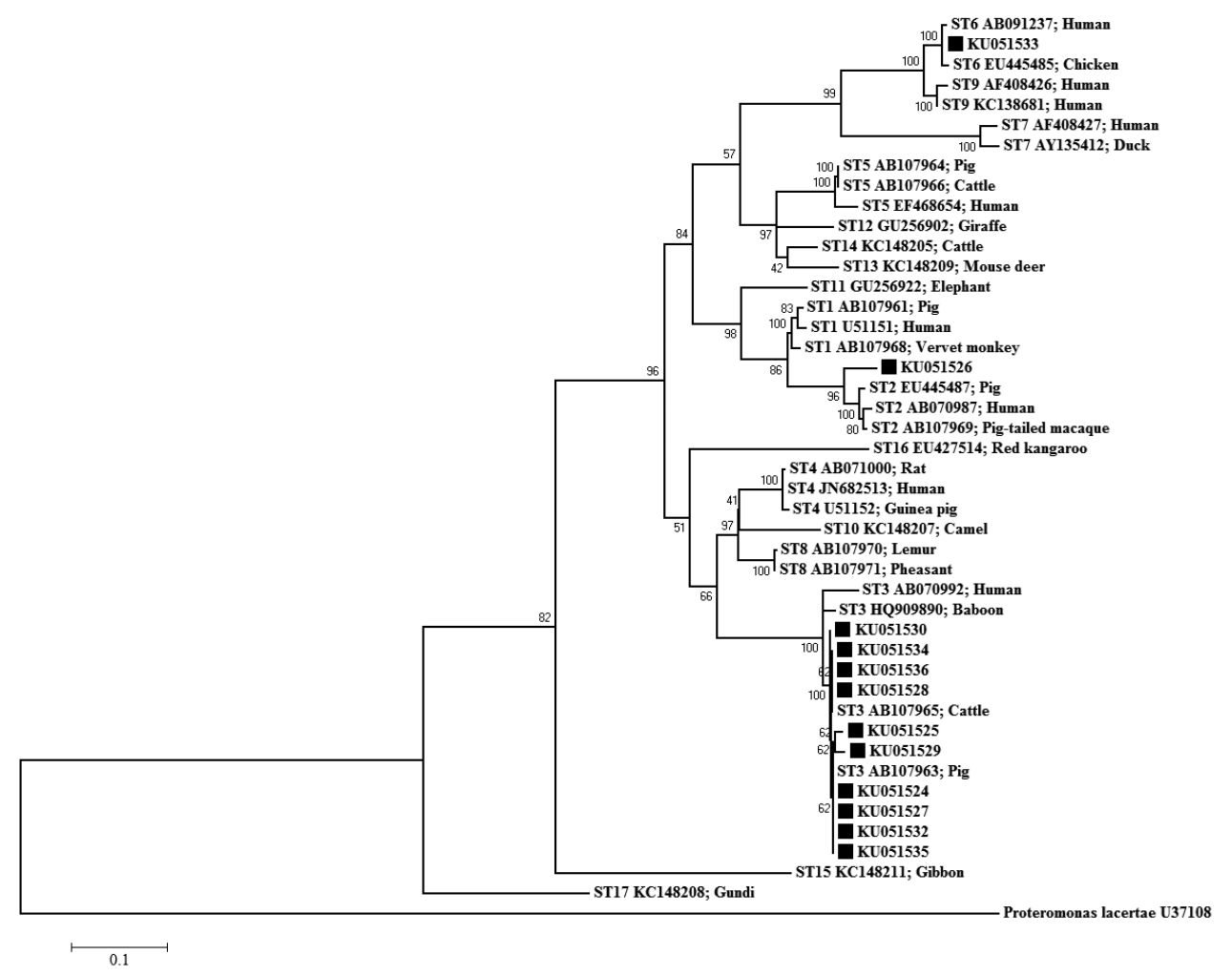

Fig. 3. Maximum-likelihood phylogenetic analysis of Blastocystis SSU rDNA sequences. Black boxes indicate the sequences identified in this study. 
pigs, cattle, monkeys, and chickens. Zoonotic STs have been isolated from these animals, and they may therefore act as reservoir hosts for this protozoan and facilitate its zoonotic transmission. Zoonotic transmission is considered an important mode of Blastocystis infection in humans, and most infections occur via the fecal-oral route.

To date, the genetic diversity of this protozoan has been demonstrated with SSU rRNA gene analyses, which have detected at least 17 distinct STs [4]. ST1-ST9 have been reported in humans, and ST3 is the most prevalent. In this study, ST3 was the predominant subtype, followed by ST2 and ST6. The findings of this study are consistent with those of several studies conducted in many countries, including Singapore, Turkey, Bangladesh, and Egypt $[2,6,13,14]$, which all reported ST3 as the predominant subtype. However, this subtype has also been isolated from animals such as pigs, dogs, cattle, and non-human primates [15]. Surprisingly, ST1 was not detected in the present study, although several studies in Thailand have reported that ST1 is a common subtype [16-18]. This discrepancy could be attributable to differences in the study areas and study populations investigated, revealing different subtype distributions. We also observed ST6 in a 1-year-old child. ST6 is considered a typical 'avian' subtype [19], and is rare in nonavian hosts. The infection may have been transmitted by the unwashed hands of the parents or carers, after their contact with animals, or when the child was crawling on the ground in areas contaminated with Blastocystis cysts. This clearly demonstrates that animals are potential risk factors for Blastocystis infection and should be considered zoonotic sources.

In this study, the PCR primers that we used amplified the partial SSU rRNA gene [2], which contains highly variable nucleotides that allow Blastocystis to be differentiated into subtypes. This sequence also allows the construction of reliable phylogenetic trees. We believed that it is one of the best techniques for Blastocystis subtyping, instead of sequencing complete SSU rRNA gene. However, the 'barcode region', a 600-bp 5' region of Blastocystis SSU rRNA, is also recommended for Blastocystis subtyping [20]. It reduces the time and the costs of the procedure insofar as the sequence can be amplified with only a single round of PCR. Therefore, the 'barcode' PCR is a useful alternative method for large epidemiological studies.

The ML tree indicated that all the Blastocystis-positive samples were potentially involved in zoonotic transmission, as shown in Fig. 3. ST3 has been reported in pigs, but is uncommon. Thathaisong et al. [18] demonstrated that ST1 was common in pigs kept at an army base in Chonburi Province. In the present study, the individuals infected with ST3 may have acquired Blastocystis from pigs (person-to-pig or pig-to-person transmission via the fecal-oral route), because we observed that their livestock (pigs, chicken, and cattle) were regularly kept under or near their houses. However, stools must be collected from all the animals in the infected houses to test this assumption. It is difficult to avoid the aerosols emitted from animal stools, which could contribute to the transmission of Blastocystis in these houses (on the ground), and frequent animal contact may increase the risk of Blastocystis infection in this area.

In conclusion, the risk of Blastocystis zoonotic infection in these villagers was considered in this study. This risk can involve a combination of factors, including the traditional culture, human activities, and animal contact (pigs, cattle, and chickens), all of which increase the risk of Blastocystis infection in the study area, even though the rate of Blastocystis infection was relatively low in this study. The villagers must have access to proper health education regarding the prevention of parasitic infections because they do not understand the dangers associated with contact with animals infected with pathogenic organisms. They should also be encouraged to improve their personal hygiene and community health. Further studies are required to investigate the Blastocystis STs in the animals living in these villages.

\section{ACKNOWLEDGMENTS}

We would like to thank all the participants and staff of the Department of Clinical Microscopy, Faculty of Allied Health Sciences, Chulalongkorn University, Bangkok, Thailand for their help in the collection of the stool samples. This research was supported by the National Research University Project, Office of Higher Education Commission, Thailand (WCU-58001-HR).

\section{CONFLICT OF INTEREST}

The authors declare that they have no conflicts of interest.

\section{REFERENCES}

1. Tan KS. New insights on classification, identification, and clinical relevance of Blastocystis spp. Clin Microbiol Rev 2008; 21: 639-665.

2. Wong KH, Ng GC, Lin RT, Yoshikawa H, Taylor MB, Tan KS. 
Predominance of subtype 3 among Blastocystis isolates from a major hospital in Singapore. Parasitol Res 2008; 102: 663-670.

3. Roberts T, Barratt J, Harkness J, Ellis J, Stark D. Comparison of microscopy, culture, and conventional polymerase chain reaction for detection of Blastocystis sp. in clinical stool samples. Am J Trop Med Hyg 2011; 84: 308-312.

4. Alfellani MA, Taner-Mulla D, Jacob AS, Imeede CA, Yoshikawa H, Stensvold CR, Clark CG. Genetic diversity of Blastocystis in livestock and zoo animals. Protist 2013; 164: 497-509.

5. Rene BA, Stensvold CR, Badsberg JH, Nielsen HV. Subtype analysis of Blastocystis isolates from Blastocystis cyst excreting patients. Am J Trop Med Hyg 2009; 80: 588-592.

6. Souppart L, Moussa H, Cian A, Sanciu G, Poirier P, El Alaoui H, Delbac F, Boorom K, Delhaes L, Dei-Cas E, Viscogliosi E. Subtype analysis of Blastocystis isolates from symptomatic patients in Egypt. Parasitol Res 2010; 106: 505-511.

7. Clark CG. Extensive genetic diversity in Blastocystis hominis. Mol Biochem Parasitol 1997; 87: 79-83.

8. Larkin MA, Blackshields G, Brown NP, Chenna R, McGettigan PA, McWilliam H, Valentin F, Wallace IM, Wilm A, Lopez R, Thompson JD, Gibson TJ, Higgins DG. Clustal W and Clustal X version 2.0. Bioinformatics 2007; 23: 2947-2948.

9. Tamura K, Stecher G, Peterson D, Filipski A, Kumar S. MEGA6: Molecular Evolutionary Genetics Analysis version 6.0. Mol Biol Evol 2013; 30: 2725-2729.

10. Hirata T, Nakamura H, Kinjo N, Hokama A, Kinjo F, Yamane N, Fujita J. Prevalence of Blastocystis hominis and Strongyloides stercoralis infection in Okinawa, Japan. Parasitol Res 2007; 101: 1717-1719.

11. Horiki N, Maruyama M, Fujita Y, Yonekura T, Minato S, Keneda Y. Epidemiologic survey of Blastocystis hominis infection in Japan. Am J Trop Med Hyg 1997; 56: 370-374.

12. Popruk S, Udonsom R, Koompapong K, Mahittikorn A, Kusolsuk T, Ruangsittichai J, Palasuwan A. Subtype distribution of Blastocystis in Thai-Myanmar border, Thailand. Korean J Parasitol 2015; 53: 13-19.

13. Meloni D, Sanciu G, Poirier P, El Alaoui H, Chabé M, Delhaes L, Dei-Cas E, Delbac F, Luigi Fiori P, Di Cave D, Viscogliosi E. Molecular subtyping of Blastocystis sp. isolates from symptomatic patients in Italy. Parasitol Res 2011; 109: 613-619.

14. Yoshikawa H, Wu Z, Kimata I, Iseki M, Ali IK, Hossain MB, Zaman V, Haque R, Takahashi Y. Polymerase chain reactionbased genotype classification among human Blastocystis hominis populations isolated from different countries. Parasitol Res 2004; 92: 22-29.

15. Stensvold CR, Alfellani M, Clark CG. Levels of genetic diversity vary dramatically between Blastocystis subtypes. Infect Genet Evol 2012; 12: 263-273.

16. Thathaisong U, Siripattanapipong S, Mungthin M, Pipatsatitpong D, Tan-Ariya P, Naaglor T, Leelayoova S. Identification of Blasto- cystis subtype 1 variants in the Home for Girls, Bangkok, Thailand. Am J Trop Med Hyg 2013; 88: 352-358.

17. Leelayoova S, Siripattanapipong S, Thathaisong U, Naaglor T, Taamasri P, Piyaraj P, Mungthin M. Drinking water: a possible source of Blastocystis spp. subtype 1 infection in schoolchildren of a rural community in central Thailand. Am J Trop Med Hyg 2008; 79: 401-406.

18. Thathaisong U, Worapong J, Mungthin M, Tan-Ariya P, Viputtigul K, Sudatis A, Noonai A, Leelayoova S. Blastocystis isolates from a pig and a horse are closely related to Blastocystis hominis. J Clin Microbiol 2003; 41: 967-975.

19. Stensvold CR, Suresh GK, Tan KS, Thompson RC, Traub RJ, Viscogliosi E, Yoshikawa H, Clark CG. Terminology for Blastocystis subtypes-a consensus. Trends Parasitol 2007; 23: 93-96.

20. Scicluna SM, Tawari B, Clark CG. DNA barcoding of Blastocystis. Protist 2006; 157: 77-85.

21. Abe N. Molecular and phylogenetic analysis of Blastocystis isolates from various hosts. Vet Parasitol 2004; 120: 235-242.

22. Silberman JD, Sogin ML, Leipe DD, Clark CG. Human parasite finds taxonomic home. Nature 1996; 380: 398.

23. Rivera WL. Phylogenetic analysis of Blastocystis isolates from animal and human hosts in the Philippines. Vet Parasitol 2008; 156: 178-182.

24. Arisue N, Hashimoto T, Yoshikawa H. Sequence heterogeneity of the small subunit ribosomal RNA genes among Blastocystis isolates. Parasitology 2003; 126: 1-9.

25. Stensvold CR, Clark CG. Investigation of the molecular epidemiology of Blastocystis by use of a multi-locus sequence typing system for subtype 3. Unpublished data.

26. Stensvold CR, Alfellani M, Clark CG. Levels of genetic diversity vary dramatically between Blastocystis subtypes. Infect Genet Evol 2012; 12: 263-273.

27. Yan MY, Su LS, Lai YR, Ye HJ, Liao H, Chen FG, Luo PX, Hou PZ, Lai FX. Phylogenetic analysis of Blastocystis hominis isolates in China. Unpublished data.

28. Noël C, Peyronnet C, Gerbod D, Edgcomb VP, Delgado-Viscogliosi P, Sogin ML, Capron M, Viscogliosi E, Zenner L. Phylogenetic analysis of Blastocystis isolates from different hosts based on the comparison of small-subunit rRNA gene sequences. Mol Biochem Parasitol 2003; 126: 119-123.

29. Engsbro AL, Stensvold CR. Blastocystis: to treat or not to treat... but how? Clin Infect Dis 2012; 55: 1431-1432.

30. Parkar U, Traub RJ, Vitali S, Elliot A, Levecke B, Robertson I, Geurden T, Steele J, Drake B, Thompson RC. Molecular characterization of Blastocystis isolates from zoo animals and their animal-keepers. Vet Parasitol 2010; 169: 8-17.

31. Yoshikawa H. Phylogenetic studies of Blastocystis isolates from zoo marsupial mammals inferred from the small subunit ribosomal RNA gene sequences. Unpublished data. 